\title{
Addiction care in crisis: evidence should drive progressive policy and practice
}

Kamaldeep S. Bhui, Peter Byrne, Diane Goslar and Julia Sinclair

\section{Summary}

Addictions are challenging health and social problems that need to be addressed to preserve and promote good mental health and ensure that individuals within society lead healthy and productive lives. Tackling addictions is complex and requires communities, public health, specialist services, and local and national government to act in unison and implement evidence-based interventions. This editorial raises systemic issues that need attention and proposes a range of systemic options.

\section{Declaration of interest}

K.S.B. is Editor-in-Chief of the British Journal of Psychiatry. The other authors declare no conflict of interest.

\section{Keywords}

Addiction; policy; substance use disorders; drugs of dependence disorders; opiate disorders.

\section{Copyright and usage}

(C) The Royal College of Psychiatrists 2019
Kamaldeep S. Bhui (pictured) is professor of cultural psychiatry and epidemiology and head of centre for psychiatry at Queen Mary University of London, UK. Peter Byrne is a consultant liaison psychiatrist at the Royal London Hospital and visiting professor at the University of Strathclyde, UK. Diane Goslar is an expert by experience and advisor on alcohol and drugs issues for the Royal College of Psychiatrists. Julia Sinclair is a professor and honorary consultant addiction psychiatrist at the University of Southampton and University Hospitals Southampton NHS Foundation Trust, UK.

We are in the midst of a crisis in the organisation and delivery of addictions services in the UK. Controversial National Health Service reforms in 2012 (championed by the then secretary of state for health) relocated responsibility for addictions treatment to local government, resulting in a reduction of over $30 \%$ in budgets for addictions treatment. ${ }^{1}$ As a result, most specialist addictions services are inadequately resourced to help vulnerable people with complex needs, reflecting societal attitudes and a political ideology that consider substance use disorders to be only self-inflicted lifestyle choices rather than being linked with health conditions. These attitudes and policy directions may contribute to the rising death rates from cocaine and opioid use in England and Wales. Other contributors include an ageing cohort of opioid users with addictions or dependence following long-term prescribing for chronic pain. ${ }^{2}$ Inappropriate use and prescribing of benzodiazepines, antipsychotics and gabapentinoids ${ }^{3}$ are also implicated in the rising mortality and falling quality of life among some vulnerable groups.

Mortality rises when we neglect evidence-based harm reduction strategies. ${ }^{1}$ An abstinence-only approach ${ }^{4}$ condemns many people with addictions to a limited and often ineffective range of treatment options, and puts their lives at risk. ${ }^{3}$ For example, without access to take-home naloxone (for which there is a strong evidence base), people who relapse are more likely to die of accidental overdose.

Deaths due to addictions, like many health conditions, are overrepresented in the most deprived parts of the country. ${ }^{2}$ Poverty and socioeconomic disadvantage limit choices and opportunities, and chronic adversity may result in excessive use of alcohol, nicotine and other psychoactive substances.

One subset of the population, those with or at risk of severe mental illness and comorbid substance use, will have more complex needs that are not easily met within existing commissioned services, and so are likely to be over-represented in drug-related deaths. Cannabis and especially skunk use elevate the risk of developing psychoses and complicating care and treatment of people with psychoses.

Paradoxically, some illegal substances may have therapeutic benefits when used as self-medication. For example, trials of psychoactive substances for treatment-resistant depression and cannabidiol-based products show potential benefit for people with chronic pain, multiple sclerosis and Parkinson's disease.

There is already a disconnection between policies for managing the health harms of legal drugs (e.g. alcohol and tobacco) and those of illicit substances, which seem especially prone to stigma and negative value judgements that fail to grasp the dynamic interactions between biological, psychosocial and environmental drivers of addiction. Progressive policies in Scotland, including minimum unit alcohol pricing, demonstrate the effective combination of evidenced public health principles with investment in substance use services. Since the 2012 reforms in England, knowledge, skills and the investment needed for effective recognition and management of addiction have been lost from the infrastructure at every level (personal, clinical and societal). This delivers poor outcomes for everyone.

Decriminalisation and regulation of substance use is an option currently not under discussion by government but this additional lever is essential to consider, alongside better standards of care and access to addictions services and specialists. Any new legal framework must be firmly linked to a population-based approach to education and risk reduction, robust evaluation of outcomes and the necessary resources to implement them. The failure to implement policy is a key cause of poor health gains.

Decriminalisation may save police resources and avoid wasteful attention on minor misdemeanours, permitting greater focus on those with more severe offending such as theft and violence. ${ }^{5}$ Criminalisation of khat in the Netherlands reduced casual use but those with severe complex needs were neglected and their use was unmanaged. Where there are clear mental health consequences or potential for addiction, health services must be commissioned to provide essential evidence-based care. Local authorities must provide a proportionate response to improve housing, tackle poverty, support addicted parents, strengthen child protection and care, and develop education opportunities for vulnerable families.

Decriminalisation risks unintended consequences. The fear is that minor drug use may act as a gateway to more dangerous 
misuse and, for those with high levels of impulsivity, related psychological disorders. However, there is little evidence that this happens where there is decriminalisation.

For people living with mental illnesses, substances may aggravate poor health outcomes or offending behaviour. Considerable research needs to be undertaken to reduce these uncertainties. This should be progressed without delay alongside any reforms in healthcare, addictions services and legislation. We can learn from international examples and case studies where decriminalisation has been productive, for example, in Portugal or the USA where a four-decade 'war' on drugs has failed.

Accepting that social and political contexts may differ and influence the likely effectiveness of policies, international evidence needs careful translation. The UK has led effective harm reduction strategies and then abandoned them for no good reason. ${ }^{1,4}$ Decriminalisation plus regulation may offer a more productive way forward, although this must include greater regulation of existing and new providers than we have seen, for example, in the alcohol, tobacco, gambling or food industries. Clearly, this should not be seen to disempower or remove individual responsibility; challenge is a necessary component of treating addictions, but challenge alone is insufficient, especially in the absence of high-quality treatment and relapse prevention services. As access to treatment in local authority services is lost and specialist training is in critical decline, we are allowing an evidence-based known solution and preventive approach to be neglected and forgotten, only to await a crisis in which knowledge can be rediscovered and applied. The impact on lost lives and health cannot be reversed. We also need to consider progressive policies and legislation that will build on the evidence base rather than simply reconstruct known solutions and lament their limitations.
Kamaldeep S. Bhui (D), CBE, MD, FRCPSych, Professor of Cultural Psychiatry and Epidemiology, Head of Centre for Psychiatry, Barts \& The London School of Medicine and Dentistry, Queen Mary University of London; and Honorary Consultant Psychiatrist, East London NHS Foundation Trust, UK; Peter Byrne, MD, MRCPsych, Consultant Liaison Psychiatrist, Royal London Hospital; and Visiting Professor, University of Strathclyde, UK; Diane Goslar, BSC ALA, is an Expert by Experience and Advisor on alcohol and drugs issues and policies for the Royal College of Psychiatrists; Julia Sinclair (D., MB, BS, MRCPsych, DPhil, Professor and Honorary Consultant Addiction Psychiatrist, University of Southampton and University Hospitals Southampton NHS Foundation Trust, UK.

Correspondence: Kamaldeep S. Bhui, Centre for Psychiatry, Wolfson Institute of Preventive Medicine, Barts and The London School of Medicine, Old Anatomy Building, Charterhouse Square, London EC1M 6BQ, UK. Email: k.s.bhui@qmul.ac.uk

First received 13 May 2019, final revision 16 May 2019, accepted 24 May 2019

\section{Acknowledgement}

We thank colleagues who commented on earlier drafts: Anne Lingford Hughes.

\section{References}

1 Drummond C. Cuts to addiction services are a false economy. BMJ 2017; 357: j2704.

2 Pierce M, Millar T, Robertson JR, Bird SM. Ageing opioid users' increased risk of methadone-specific death in the UK. Int J Drug Policy 2018; 55: 121-27.

3 Gomes T, Khuu W, Martins D, Tadrous M, Mamdani MM, Paterson JM, et al. Contributions of prescribed and non-prescribed opioids to opioid related deaths: population based cohort study in Ontario, Canada. BMJ 2018; 362: k3207.

4 Luty J. Promoting abstinence for drug users is about saving money not science. BMJ 2013; 346: f1481.

5 Hughes CE, Stevens A. What can we learn from the Portuguese decriminalization of illicit drugs? The British Journal of Criminology 2010; 50: 999-1022. 